\title{
Comparison of in vivo postexercise phosphocreatine recovery and resting ATP synthesis flux for the assessment of skeletal muscle mitochondrial function
}

\section{Citation for published version (APA):}

Broek, van den, N. M. A., Ciapaite, J., Nicolay, K., \& Prompers, J. J. (2010). Comparison of in vivo postexercise phosphocreatine recovery and resting ATP synthesis flux for the assessment of skeletal muscle mitochondrial function. American Journal of Physiology : Cell Physiology, 299(5), C1136-C1143.

https://doi.org/10.1152/ajpcell.00200.2010

DOI:

10.1152/ajpcell.00200.2010

Document status and date:

Published: 01/01/2010

\section{Document Version:}

Publisher's PDF, also known as Version of Record (includes final page, issue and volume numbers)

\section{Please check the document version of this publication:}

- A submitted manuscript is the version of the article upon submission and before peer-review. There can be important differences between the submitted version and the official published version of record. People interested in the research are advised to contact the author for the final version of the publication, or visit the DOI to the publisher's website.

- The final author version and the galley proof are versions of the publication after peer review.

- The final published version features the final layout of the paper including the volume, issue and page numbers.

Link to publication

\footnotetext{
General rights

- You may freely distribute the URL identifying the publication in the public portal. follow below link for the End User Agreement:

www.tue.nl/taverne

\section{Take down policy}

If you believe that this document breaches copyright please contact us at:

openaccess@tue.nl

providing details and we will investigate your claim.
}

Copyright and moral rights for the publications made accessible in the public portal are retained by the authors and/or other copyright owners and it is a condition of accessing publications that users recognise and abide by the legal requirements associated with these rights.

- Users may download and print one copy of any publication from the public portal for the purpose of private study or research.

- You may not further distribute the material or use it for any profit-making activity or commercial gain

If the publication is distributed under the terms of Article $25 \mathrm{fa}$ of the Dutch Copyright Act, indicated by the "Taverne" license above, please 


\section{Comparison of in vivo postexercise phosphocreatine recovery and resting ATP synthesis flux for the assessment of skeletal muscle mitochondrial function}

N. M. A. van den Broek, J. Ciapaite, K. Nicolay and J. J. Prompers

Am J Physiol Cell Physiol 299:C1136-C1143, 2010. First published 28 July 2010;

doi:10.1152/ajpcell.00200.2010

You might find this additional info useful...

This article cites 67 articles, 31 of which can be accessed free at:

http://ajpcell.physiology.org/content/299/5/C1136.full.html\#ref-list-1

This article has been cited by 1 other HighWire hosted articles

The Association of Growth Hormone Parameters with Skeletal Muscle Phosphocreatine

Recovery in Adult Men

Hideo Makimura, Takara L. Stanley, Noelle Sun, Mirko I. Hrovat, David M. Systrom and

Steven K. Grinspoon

JCEM, March , 2011; 96 (3): 817-823.

[Abstract] [Full Text] [PDF]

Updated information and services including high resolution figures, can be found at:

http://ajpcell.physiology.org/content/299/5/C1136.full.html

Additional material and information about AJP - Cell Physiology can be found at: http://www.the-aps.org/publications/ajpcell

This infomation is current as of November 2, 2011.

AJP - Cell Physiology is dedicated to innovative approaches to the study of cell and molecular physiology. It is published 12 times a year (monthly) by the American Physiological Society, 9650 Rockville Pike, Bethesda MD 20814-3991. Copyright $\odot 2010$ by the American Physiological Society. ISSN: 0363-6143, ESSN: 1522-1563. Visit our website at http://www.the-aps.org/. 


\title{
Comparison of in vivo postexercise phosphocreatine recovery and resting
}

\section{ATP synthesis flux for the assessment of skeletal muscle mitochondrial}

\section{function}

\author{
N. M. A. van den Broek, ${ }^{1}$ J. Ciapaite,,${ }^{1,2}$ K. Nicolay, ${ }^{1}$ and J. J. Prompers ${ }^{1}$ \\ ${ }^{1}$ Biomedical NMR, Department of Biomedical Engineering, Eindhoven University of Technology, Eindhoven; and ${ }^{2}$ The \\ Netherlands Consortium for Systems Biology, Den Haag, The Netherlands
}

Submitted 27 May 2010; accepted in final form 23 July 2010

\begin{abstract}
van den Broek NM, Ciapaite J, Nicolay K, Prompers JJ. Comparison of in vivo postexercise phosphocreatine recovery and resting ATP synthesis flux for the assessment of skeletal muscle mitochondrial function. Am J Physiol Cell Physiol 299: C1136-C1143, 2010. First published July 28, 2010; doi:10.1152/ajpcell.00200.2010._ ${ }^{31} \mathrm{P}$ magnetic resonance spectroscopy (MRS) has been used to assess skeletal muscle mitochondrial function in vivo by measuring 1) phosphocreatine $(\mathrm{PCr})$ recovery after exercise or 2) resting ATP synthesis flux with saturation transfer (ST). In this study, we compared both parameters in a rat model of mitochondrial dysfunction with the aim of establishing the most appropriate method for the assessment of in vivo muscle mitochondrial function. Mitochondrial dysfunction was induced in adult Wistar rats by daily subcutaneous injections with the complex I inhibitor diphenyleneiodonium (DPI) for $2 \mathrm{wk}$. In vivo ${ }^{31} \mathrm{P}$ MRS measurements were supplemented by in vitro measurements of oxygen consumption in isolated mitochondria. Two weeks of DPI treatment induced mitochondrial dysfunction, as evidenced by a $20 \%$ lower maximal ADP-stimulated oxygen consumption rate in isolated mitochondria from DPI-treated rats oxidizing pyruvate plus malate. This was paralleled by a $46 \%$ decrease in in vivo oxidative capacity, determined from postexercise $\mathrm{PCr}$ recovery. Interestingly, no significant difference in resting, ST-based ATP synthesis flux was observed between DPI-treated rats and controls. These results show that $\mathrm{PCr}$ recovery after exercise has a more direct relationship with skeletal muscle mitochondrial function than the ATP synthesis flux measured with ${ }^{31} \mathrm{P}$ ST MRS in the resting state.
\end{abstract}

${ }^{31} \mathrm{P}$ magnetic resonance spectroscopy; saturation transfer; high-resolution respirometry; complex I inhibition; diphenyleneiodonium

MITOCHONDRIA play a pivotal role in many cellular processes, the most important function being the production of energy in the form of ATP through a process termed oxidative phosphorylation. In the last decade, mitochondria gained interest in the field of insulin resistance (IR) and type 2 diabetes (T2D) (21, $34,43,49,53,55)$. Based on the in vivo observation that ATP synthesis flux in resting skeletal muscle is lower in insulinresistant subjects and offspring of T2D patients compared with healthy controls $(38,39)$, it has been hypothesized that skeletal muscle mitochondrial dysfunction is a predisposing factor for IR and/or T2D. The proposed mechanism links muscle mitochondrial dysfunction to impaired fatty acid metabolism, which subsequently leads to the accumulation of intramyocellular lipids and lipid intermediates (e.g., diacylglycerol and ceramides) that interfere with the insulin signaling cascade (68).

Address for reprint requests and other correspondence: J. J. Prompers, Eindhoven Univ. of Technology, Biomedical NMR, PO Box 513, 5600 MB Eindhoven, The Netherlands (e-mail: j.j.prompers@tue.nl).
The role of skeletal muscle mitochondrial dysfunction in the development of IR and/or T2D has been investigated using a variety of techniques $(12,16-18,24,31-33,37-40,45,48$, 52). In vitro methodologies, like the determination of gene expression levels, enzyme activities, mitochondrial content, morphology, and respiration, provide specific information on different aspects of mitochondrial energy production, but the results cannot be directly translated to in vivo mitochondrial function. ${ }^{31} \mathrm{P}$ magnetic resonance spectroscopy (MRS) provides a noninvasive tool to monitor the energetic status of the cell in vivo by measuring intracellular phosphorous containing metabolites; i.e., phosphocreatine (PCr), ATP, and inorganic phosphate $\left(\mathrm{P}_{\mathrm{i}}\right) .{ }^{31} \mathrm{P} \mathrm{MR}$ spectra of resting skeletal muscle are relatively constant, even in diseased states, and to assess impairments in mitochondrial energy production one needs to perturb either the chemical or the magnetic equilibrium as described below.

The resting $\mathrm{P}_{\mathrm{i}} \rightarrow$ ATP flux $\left(V_{\mathrm{ATP}}\right)$ can be determined by saturating the $\gamma$-ATP peak and monitoring the effect of this perturbation on the $\mathrm{P}_{\mathrm{i}}$ magnetization in a so-called ${ }^{31} \mathrm{P}$ saturation transfer $(\mathrm{ST})$ experiment $(3,5)$. Assuming that $V_{\mathrm{ATP}}$ is predominantly reflecting oxidative ATP synthesis by the $\mathrm{F}_{1} \mathrm{~F}_{0^{-}}$ ATP synthase in the mitochondria, $V_{\text {ATP }}$ has been taken as a measure for mitochondrial function $(39,40)$. However, the interpretation of ${ }^{31} \mathrm{P}$ ST data is not straightforward. The lower ATP synthesis rates in resting muscle of insulin-resistant subjects $(38,39)$ could actually reflect a normal regulatory response to a lower energy demand caused by impaired insulin signaling rather than an impairment of intrinsic mitochondrial function $(1,26,51,65)$. Moreover, $V_{\text {ATP }}$ obtained from ${ }^{31} \mathrm{P}$ ST measurements is composed of both mitochondrial ATP synthase flux and glycolytic exchange flux, with the latter contributing by as much as $80 \%$ at rest $(3,4,6,26,27)$. Therefore, decreased resting $V_{\mathrm{ATP}}$ does not necessarily reflect a mitochondrial defect.

As an alternative to the resting state ST experiment described above, the metabolic steady state of the muscle; i.e., the chemical equilibrium, can be disturbed during exercise. During recovery from exercise, the $\mathrm{PCr}$ pool is replenished purely through oxidative ATP synthesis $(42,46,58)$. Because the creatine kinase reaction is much faster than oxidative ATP production (64), the measurement of $\mathrm{PCr}$ recovery using dynamic ${ }^{31} \mathrm{P}$ MRS after exercise provides an alternative method to determine the rate of oxidative ATP synthesis. The $\mathrm{PCr}$ recovery rate constant $\left(k_{\mathrm{PCr}}\right)$ thus reflects in vivo muscle mitochondrial oxidative capacity; i.e., the maximal capacity for oxidative ATP production, which is typically one order of magnitude higher than the ATP synthesis rate at rest. There- 
fore, the postexercise $\mathrm{PCr}$ recovery rate constant might be a more suitable measure for in vivo mitochondrial function compared with the resting ATP synthesis flux.

In this study, we compared in vivo ${ }^{31} \mathrm{P}$ MRS postexercise $\mathrm{PCr}$ recovery and resting ATP synthesis flux in a rat model of mitochondrial dysfunction with the aim of establishing the most appropriate method for the assessment of in vivo skeletal muscle mitochondrial function. Mitochondrial dysfunction was induced by daily subcutaneous injections with diphenyleneiodonium (DPI), which irreversibly inhibits complex I (NADHubiquinone reductase) of the respiratory chain $(9,10,30,44)$. In vivo measurements were supplemented by in vitro measurements of oxygen consumption in isolated mitochondria to confirm inhibition of complex I and to compare in vivo and in vitro measurements of mitochondrial function.

\section{MATERIALS AND METHODS}

Animals. Adult male Wistar rats $(364 \pm 18 \mathrm{~g}, 14 \mathrm{wk}$ old, $n=16$, Charles River Laboratories, The Netherlands) were housed in pairs at $20^{\circ} \mathrm{C}$ and $50 \%$ humidity, with a $12: 12$-h light-dark cycle. Rats were given ad libitum access to water and normal chow $[9.2 \%$ calories from fat, $67.2 \%$ calories from carbohydrates, $23.6 \%$ calories from proteins (R/M-H diet, Ssniff Spezialdiäten, Soest, Germany)]. DPI (Toronto Research Chemicals, North York, Ontario, Canada) was dissolved in a warm $5 \%$ (wt/vol) glucose solution $(1.3 \mathrm{mg} / \mathrm{ml})$ and was injected daily subcutaneously at $1 \mathrm{mg} / \mathrm{kg}$ body wt for $11 \pm 2$ days $(n=8)(10)$. Control animals received similar volumes of subcutaneously injected $5 \%$ (wt/vol) glucose solution $(n=8)$.

The day after in vivo MRS measurements, rats were euthanized by incising the inferior vena cava under anesthesia. Immediately thereafter, half of one tibialis anterior (TA) was freeze clamped using liquid nitrogen-cooled tongs (36) and stored at $-80^{\circ} \mathrm{C}$ for ATP determination. The other part of the TA was frozen in liquid nitrogen and stored at $-80^{\circ} \mathrm{C}$ for the determination of mitochondrial DNA (mtDNA) content. The second TA muscle (fresh) was used for isolation of mitochondria. All experimental procedures were reviewed and approved by the Animal Ethics Committee of Maastricht University.

${ }^{31} P$ MRS. All MRS measurements were performed on a 6.3-Tesla horizontal Bruker MR system (Bruker, Ettlingen, Germany), 14 days after the start of treatment. Animals were anesthetized using isoflurane (Forene) (1-2\%) with medical air $(0.6 \mathrm{l} / \mathrm{min})$, and body temperature was maintained at $35.5 \pm 0.5^{\circ} \mathrm{C}$ using heating pads. Respiration was monitored using a pressure sensor registering thorax movement (Rapid Biomedical, Rimpar, Germany).

Resting $V_{\mathrm{ATP}}$ and postexercise $k_{\mathrm{PCr}}$ were measured in the TA by in vivo ${ }^{31} \mathrm{P}$ MRS. ${ }^{31} \mathrm{P}$ MRS was applied using a combination of a circular ${ }^{1} \mathrm{H}$ surface coil $(40 \mathrm{~mm})$ for making MR images and localized shimming and an ellipsoid ${ }^{31} \mathrm{P}$ MRS surface coil $(10 / 18 \mathrm{~mm})$, positioned over the TA as described previously (11). ${ }^{31} \mathrm{P}$ MR spectra were acquired applying an adiabatic excitation pulse with a flip angle of $90^{\circ}$. A fully relaxed (TR $=25 \mathrm{~s}, 32$ averages) spectrum was measured at rest, followed by the ST experiment in resting TA muscle to determine $V_{\text {ATP. Two spectra }}$ (TR $=10.4 \mathrm{~s}, 128$ averages) were acquired for each ST experiment: a spectrum with frequency-selective saturation of the $\gamma$-ATP peak yielding the steady-state $P_{i}$ magnetization in the presence of saturation $\left(\mathrm{M}^{\prime}\right)$ and a reference spectrum with saturation at a downfield frequency, equidistant from $\mathrm{P}_{\mathrm{i}}$, yielding the equilibrium $P_{i}$ magnetization $\left(M_{0}\right)$, both with a saturation pulse length of $10 \mathrm{~s}$. The apparent longitudinal relaxation time of $\mathrm{P}_{\mathrm{i}}\left(T_{1}^{\prime}\right)$ was determined by performing an eight-point inversion recovery experiment with an adiabatic full passage pulse for inversion and with $\gamma$-ATP saturation before (10 s) and during the inversion delay (inversion times $=0.01,1,2,4,6.5,9.5,13$, and $17 \mathrm{~s}, 32$ averages). The total duration of the ST and inversion recovery experiments was about $2 \mathrm{~h}$.

After the ST experiments, time series of ${ }^{31} \mathrm{P}$ MR spectra $(\mathrm{TR}=5$ s, 4 averages) before, during, and after muscle contractions were acquired. Muscle contractions were induced by electrical stimulation of the TA via subcutaneously implanted electrodes positioned along the distal N. Peroneus Communis (11). The stimulation protocol consisted of a series of stimulation pulses, applied every second, for a duration of $2 \mathrm{~min}$. Stimulation pulse length was $100 \mathrm{~ms}$, frequency was $80 \mathrm{~Hz}$, and stimulation voltage varied between 2.5 and $4 \mathrm{~V}$. Recovery was followed for $15 \mathrm{~min}$. Three to four time series were measured for each rat.

${ }^{31} \mathrm{P}$ MR spectra were fit in the time domain by using an advanced magnetic resonance (AMARES) nonlinear least squares algorithm in the $\mathrm{jMRUI}$ software package (jMRUI V2.1). $\mathrm{PCr}$ and $\mathrm{P}_{\mathrm{i}}$ peaks were fit to Lorentzian line shapes, whereas $\gamma-, \alpha$, and $\beta$-ATP signals were fit with Gaussian line shapes. Besides the cytosolic $\mathrm{P}_{\mathrm{i}}$ signal, a second, smaller $\mathrm{P}_{\mathrm{i}}$ peak was observed in the spectra at a frequency $\sim 0.3 \mathrm{ppm}$ downfield from the cytosolic $P_{i}$ resonance. The two $P_{i}$ signals were separately fitted, and the line widths were constrained with respect to the line width of the PCr signal. For the dynamic MRS spectra, the two $P_{i}$ signals could not be distinguished, and a single $P_{i}$ peak was fit to a Gaussian line shape. Concentrations of $\mathrm{PCr}$ and $\mathrm{P}_{\mathrm{i}}$ were determined relative to the ATP concentration, which was determined in vitro from freeze clamped tissue as described below. ADP concentrations were calculated using the creatine kinase equilibrium (29), and intracellular $\mathrm{pH}$ was calculated from the chemical shift difference between $\mathrm{PCr}$ and the cytosolic $\mathrm{P}_{\mathrm{i}}$ resonance (58).

The $T_{1}^{\prime}$ relaxation time of $\mathrm{P}_{\mathrm{i}}$ was determined by fitting the inversion recovery data with a three-parameter monoexponential function using Origin (OriginPro 7.5 SR0, OriginLab, Northampton, MA). The $V_{\text {ATP }}$ exchange rate constant $\left(k_{\mathrm{Pi} \rightarrow \mathrm{ATP}}\right)$ was calculated from the $T_{1}^{\prime}$ of $\mathrm{P}_{\mathrm{i}}$ and the fractional reduction of $\mathrm{P}_{\mathrm{i}}$ magnetization upon selective saturation of $\gamma$-ATP according to: $k_{\mathrm{Pi} \rightarrow \mathrm{ATP}}=\left(1-\mathrm{M}^{\prime} / \mathrm{M}_{0}\right) / T_{1}^{\prime}$. $\mathrm{V}_{\mathrm{ATP}}$ was then calculated by multiplying $k_{\mathrm{Pi} \rightarrow \mathrm{ATP}}$ with the $\mathrm{P}_{\mathrm{i}}$ concentration at rest, as determined from the fully relaxed spectrum. The intrinsic $T_{i}$ of $P_{i}$ was calculated as $\mathrm{T}_{1}=1 /\left(1 / T_{1}^{\prime}-k_{\mathrm{Pi} \rightarrow \mathrm{ATP}}\right)$. The data of $\mathrm{PCr}$ recovery were fit to a monoexponential function using Matlab (version 7.04, Mathworks, Natick, MA) yielding a rate constant $k_{\mathrm{PCr}}$. Results from two time series with end-stimulation $\mathrm{pH}$ values higher than 6.92 (63) were averaged.

TA muscle cross-sectional area in the midbelly region of the muscle was determined from the MR images using Mathematica (version 7.0, Wolfram Research, Champaign, IL).

Determination of ATP concentration. Freeze-clamped TA muscle was powdered in liquid nitrogen, mixed with $3.25 \mathrm{ml} / \mathrm{g}$ perchloric acid $(6 \% \mathrm{wt} / \mathrm{vol})$, and homogenized for $30 \mathrm{~s}$ using an Ultra-Turrax highperformance disperser (IKA Werke, Staufen, Germany). Next, the homogenate was neutralized with $5 \mathrm{M} \mathrm{K}_{2} \mathrm{CO}_{3}$ to $\mathrm{pH} 7.4$ and centrifuged at $3,000 \mathrm{~g}$ for $10 \mathrm{~min}$ at $4^{\circ} \mathrm{C}$. ATP concentration in the supernatant was determined spectrophotometrically using the hexokinase/glucose-6-phosphate dehydrogenase coupled assay as described in detail in Ref. 60.

Isolation of mitochondria. Mitochondria were isolated from one whole TA muscle through a differential centrifugation procedure as previously described (62). Briefly, TA muscle was excised, washed in ice-cold $0.9 \% \mathrm{KCl}$, freed of connective and adipose tissue, weighed, and minced with scissors in ice-cold medium A ( $5 \mathrm{ml}$ for $1 \mathrm{~g}$ tissue) containing $150 \mathrm{mM}$ sucrose, $75 \mathrm{mM} \mathrm{KCl}, 50 \mathrm{mM}$ MOPS, $1 \mathrm{mM}$ $\mathrm{KH}_{2} \mathrm{PO}_{4}, 5 \mathrm{mM} \mathrm{MgCl} 2,1 \mathrm{mM}$ EGTA, and $0.4 \mathrm{mg} / \mathrm{ml}$ bacterial proteinase type XXIV, pH 7.4. Next, $20 \mathrm{ml}$ of medium B containing $250 \mathrm{mM}$ sucrose, $0.1 \mathrm{mM}$ EGTA, and $20 \mathrm{mM}$ MOPS, $2 \mathrm{mg} / \mathrm{ml}$ BSA, $\mathrm{pH} 7.4$ were added, and the mixture was homogenized using PotterElvehjem homogenizer. The homogenate was centrifuged at $800 \mathrm{~g}$ for $10 \mathrm{~min}, 4^{\circ} \mathrm{C}$. The resulting supernatant was centrifuged at $10,000 \mathrm{~g}$ for $10 \mathrm{~min}, 4^{\circ} \mathrm{C}$. The pellet was resuspended in $15 \mathrm{ml}$ of fresh ice-cold medium B and centrifuged at $10,000 \mathrm{~g}$ for $10 \mathrm{~min}, 4^{\circ} \mathrm{C}$. Mitochondrial 
pellet was resuspended in $100 \mu \mathrm{l}$ of medium B. Protein content was determined using BCA protein assay kit (Pierce, Thermo Fisher Scientific, Rockford, IL).

Measurement of oxygen consumption. Oxygen consumption rate was measured at $37^{\circ} \mathrm{C}$ using a two-channel high-resolution Oroboros oxygraph-2 k (Oroboros, Innsbruck, Austria). Maximal ADP-stimulated (state 3 ) oxygen consumption rate was determined in the assay medium containing $110 \mathrm{mM} \mathrm{KCl}, 20 \mathrm{mM}$ Tris, $2.3 \mathrm{mM} \mathrm{MgCl}_{2}, 5 \mathrm{mM}$ $\mathrm{KH}_{2} \mathrm{PO}_{4}, 50 \mathrm{mM}$ creatine, $4.4 \mathrm{U} / \mathrm{ml}$ creatine phosphokinase, $1 \mathrm{mM}$ $\mathrm{ATP}$, and $1 \mathrm{mg} / \mathrm{ml} \mathrm{BSA}, \mathrm{pH}$ 7.3. All measurements were performed in $1 \mathrm{ml}$ of assay medium containing $0.15 \mathrm{mg} / \mathrm{ml}$ of mitochondrial protein. To assess NADH- (through complex I) and $\mathrm{FADH}_{2}$-driven (through complex II) oxygen consumption, $5 \mathrm{mM}$ pyruvate plus $5 \mathrm{mM}$ malate and $5 \mathrm{mM}$ succinate plus $1 \mu \mathrm{M}$ rotenone were used, respectively. Oxygen consumption in resting state (state 4) was determined after addition of $1.25 \mu \mathrm{M}$ carboxyatractyloside. The signals from the oxygen electrode were recorded at 0.5 -s intervals. Data acquisition and analysis were performed using Oxygraph-2k-DatLab software version 4.2 (Oroboros).

Determination of the relative mitochondrial copy number. Genomic DNA was isolated from a 25-mg transversal slice of midbelly TA using GenElute Mammalian Genomic DNA Miniprep Kit (Sigma-Aldrich, Zwijndrecht, The Netherlands). mtDNA content relative to peroxisome proliferator-activated receptor- $\gamma$ coactivator $1 \alpha$ (PGC-1 $\alpha$ ) gene was measured using real-time PCR as described in Ref. 7. Primers for mtDNA were the following: forward primer, 5'-ACACCAAAAGGACGAACCTG-3'; reverse primer, 5'-ATGGGGAAGAAGCCCTAGAA- $3^{\prime}$; and for PGC- $1 \alpha$ : forward primer, 5'-ATGAATGCAGCGGTCTTAGC-3'; reverse primer, 5'-AACAATGGCAGGGTTTGTTC- $3^{\prime}$. The relative mtDNA copy number was calculated using $\Delta \Delta \mathrm{Ct}$ method as described in Ref. 57.

Statistical analysis. Data are presented as means \pm SD. The listed $n$ values represent the number of animals used for a particular experiment. Statistical significance of the differences was assessed using unpaired Student's $t$-tests in SPSS 16.0 statistical package (SPSS, Chicago, IL). Level of statistical significance was set at $P<$ 0.05 .

\section{RESULTS}

Animal model. Daily DPI treatment resulted in a decreased food intake $(22.1 \pm 1.0$ and $10.8 \pm 2.9 \mathrm{~g} /$ day for control and DPI-treated rats, respectively; $P<0.001)$ and a lower body weight $(\mathrm{BW})$ at the end of the DPI treatment $(375 \pm 24$ and $330 \pm 21 \mathrm{~g}$ for control and DPI-treated rats, respectively; $P=$ $0.001)$. In parallel with the $12 \%$ lower BW, TA muscle crosssectional area was $10 \%$ smaller in DPI-treated rats compared with controls at the end of the treatment $(0.43 \pm 0.03$ and $0.38 \pm 0.03 \mathrm{~cm}^{2}$ for control and DPI-treated rats, respectively; $P=0.01)$.

Mitochondrial characteristics in vitro. To assess the effect of DPI on the intrinsic in vitro mitochondrial function we determined oxygen consumption rates in mitochondria isolated from the TA muscle (results are summarized in Table 1).
Table 2. Metabolite concentrations and $\mathrm{pH}$ in tibialis anterior measured by in vivo ${ }^{31} \mathrm{P}$ magnetic resonance spectroscopy

\begin{tabular}{lccccc}
\hline \hline & \multicolumn{2}{c}{ Rest } & & \multicolumn{2}{c}{ End Stimulation } \\
\cline { 2 - 3 } \cline { 5 - 6 } & Control & DPI & & Control & DPI \\
\hline $\mathrm{pH}$ & $7.19 \pm 0.02$ & $7.21 \pm 0.02$ & & $7.07 \pm 0.06$ & $7.01 \pm 0.06$ \\
{$[\mathrm{PCr}], \mathrm{mM}$} & $47.5 \pm 2.8$ & $48.8 \pm 2.9$ & & $22.8 \pm 2.7$ & $20.9 \pm 1.2$ \\
{$\left[\mathrm{P}_{\mathrm{i}}\right], \mathrm{mM}$} & $3.0 \pm 0.4$ & $3.0 \pm 0.8$ & & $28.6 \pm 3.5$ & $31.9 \pm 2.8$ \\
{$[\mathrm{ADP}], \mu \mathrm{M}$} & $13.4 \pm 0.6$ & $13.9 \pm 0.4$ & & $84.8 \pm 10.2$ & $89.5 \pm 16.7$ \\
\hline
\end{tabular}

Data are from $n=8$ animals for each group and are expressed as means \pm $\mathrm{SD}$. $\mathrm{PCr}$, phosphocreatine; $\mathrm{P}_{\mathrm{i}}$, inorganic phosphate.

Maximal ADP-stimulated (state 3) oxygen consumption rate in the isolated mitochondria oxidizing pyruvate plus malate was $20 \%$ lower $(P<0.001)$ in the DPI-treated group compared with controls. The effect of DPI treatment on succinate oxidation was less pronounced; oxygen consumption rate in state 3 was $12 \%$ lower $(P=0.03)$ compared with controls. For both substrates oxygen consumption rates in the absence of ATP synthesis (state 4) were similar in DPI-treated and control groups.

The effect of chronic inhibition of intrinsic mitochondrial function by DPI on mitochondrial biogenesis was assessed by determining mtDNA copy number in TA muscle. The relative mtDNA copy number was not significantly different in the TA muscle of control $(2,200 \pm 323)$ and DPI-treated $(2,190 \pm$ 369) rats.

Muscle ATP concentration. ATP concentrations in TA muscle were $12.5 \pm 3.2 \mathrm{mM}$ for control rats $(n=5)$ and $11.0 \pm$ $2.5 \mathrm{mM}$ for DPI-treated rats $(n=7)$ and were not significantly different $(P=0.4)$. Because DPI treatment had no significant effect on the muscle ATP concentration, the average value for both groups combined $(11.6 \pm 2.8 \mathrm{mM})$ was taken as a reference for the in vivo MRS data analysis.

In vivo ${ }^{31} \mathrm{P} M R S$. Concentrations of $\mathrm{PCr}, \mathrm{P}_{\mathrm{i}}$, and $\mathrm{ADP}$ and the intracellular $\mathrm{pH}$ obtained from the ${ }^{31} \mathrm{P} \mathrm{MR}$ spectra recorded in resting TA muscle are summarized in Table 2. DPI treatment had no significant effect on any of these parameters.

Figure 1 shows a representative example of a ${ }^{31} \mathrm{P}$ ST spectrum measured in resting TA muscle with frequency-selective saturation of the $\gamma$-ATP peak (black) and the corresponding reference spectrum with saturation at a downfield frequency equidistant from $\mathrm{P}_{\mathrm{i}}$ (grey). From the ${ }^{31} \mathrm{P}$ ST spectra, the ratio of $\mathrm{P}_{\mathrm{i}}$ magnetization with and without saturation of $\gamma$-ATP $\left(\mathrm{M}^{\prime} /\right.$ $\mathrm{M}_{0}$ ) was determined, and this ratio was not significantly different between the groups (Table 3 ). The apparent $\mathrm{T}_{1}\left(T_{1}^{\prime}\right)$ of $\mathrm{P}_{\mathrm{i}}$ in case of saturation of $\gamma$-ATP was determined from an eight-point inversion recovery experiment, and a representative example of $\mathrm{P}_{\mathrm{i}}$ inversion recovery data and the corresponding

Table 1. Oxygen consumption rates in isolated tibialis anterior muscle mitochondria oxidizing different substrates in different metabolic states

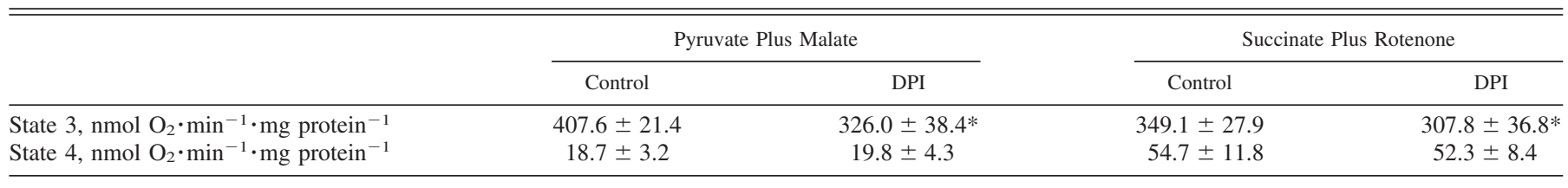

Data are from $n=7$ control and $n=8$ diphenyleneiodonium (DPI)-treated animals and are expressed as means \pm SD. State 3, maximal ADP-stimulated oxygen consumption; state 4 , oxygen consumption in the absence of ATP synthesis; $* P<0.05$ when compared with control group. 


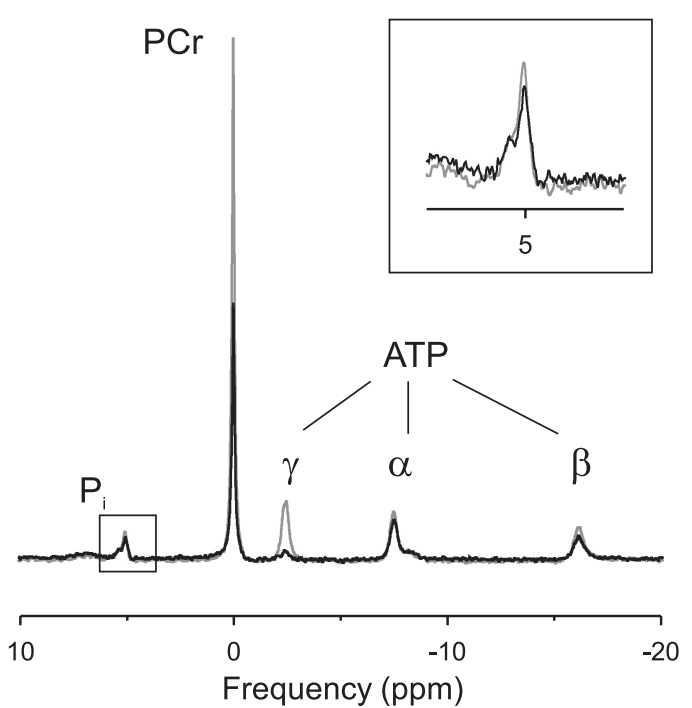

Fig. 1. Example of ${ }^{31} \mathrm{P}$ saturation transfer spectra (saturation pulse length $=10$ $\mathrm{s}, \mathrm{TR}=10.4 \mathrm{~s}, 128$ averages) with saturation of $\gamma$-ATP (black) and with saturation at a downfield frequency, equidistant from $\mathrm{P}_{\mathrm{i}}$ (grey), measured in tibialis anterior (TA) muscle of a diphenyleiodonium (DPI)-treated rat. PCr, phosphocreatine.

mono-exponential fit is shown in Fig. 2. $T_{1}^{\prime}$ values of $\mathrm{P}_{\mathrm{i}}$ were similar for control and DPI-treated animals (Table 3). The exchange rate constant $k_{\mathrm{Pi} \rightarrow \mathrm{ATP}}$ determined from $T_{1}^{\prime}$ and $\mathrm{M}^{\prime} /$ $\mathrm{M}_{0}, V_{\mathrm{ATP}}$ determined from $k_{\mathrm{Pi} \rightarrow \mathrm{ATP}}$ and the $\mathrm{P}_{\mathrm{i}}$ concentration, and the intrinsic $T_{1}$ of $\mathrm{P}_{\mathrm{i}}$ were also not significantly different between control and DPI-treated animals (Table 3 and Fig. 3A).

Dynamic ${ }^{31} \mathrm{P}$ MRS measurements during and after recovery from electrical stimulation of the TA were performed to determine the rate of $\mathrm{PCr}$ recovery after stimulation. Concentrations of $\mathrm{PCr}, \mathrm{P}_{\mathrm{i}}$, and $\mathrm{ADP}$ and the intracellular $\mathrm{pH}$ at the end of the stimulation were not significantly different between groups (Table 2). PCr concentrations during recovery were fitted with a monoexponential function (Fig. 4) yielding $k_{\mathrm{PCr}} \cdot k_{\mathrm{PCr}}$ was $46 \%$ lower in DPI-treated animals compared with control rats (Fig. 3B, $P<0.001$ ). There was no relationship between $V_{\mathrm{ATP}}$ and $k_{\mathrm{PCr}}\left(R^{2}=0.15, P=0.15\right)$.

\section{DISCUSSION}

In this study, we compared in vivo ${ }^{31} \mathrm{P}$ MRS postexercise $\mathrm{PCr}$ recovery and resting ATP synthesis flux in a rat model of

Table 3. Parameters determined from ${ }^{31} P$ saturation transfer magnetic resonance spectroscopy

\begin{tabular}{lcr}
\hline \hline & Control & \multicolumn{1}{c}{ DPI } \\
\hline $\mathrm{M}^{\prime} / \mathrm{M}_{0}$ & $0.73 \pm 0.06$ & $0.67 \pm 0.08$ \\
$T_{1}^{\prime}, \mathrm{s}$ & $3.87 \pm 0.37$ & $3.76 \pm 0.79$ \\
$T_{1}, \mathrm{~s}$ & $5.38 \pm 0.79$ & $5.69 \pm 1.33$ \\
$k_{\mathrm{Pi} \rightarrow \mathrm{ATP}, \mathrm{s}^{-1}}$ & $0.07 \pm 0.02$ & $0.09 \pm 0.04$ \\
$V_{\mathrm{ATP}}, \mu \mathrm{mol} \cdot \mathrm{g}^{-1} \cdot \mathrm{min}^{-1}$ & $8.33 \pm 1.53$ & $10.45 \pm 2.82$ \\
\hline
\end{tabular}

Data are from $n=7$ control and $n=8$ DPI-treated animals and are expressed as means $\pm \mathrm{SD}$. $\mathrm{M}^{\prime}$, magnetization of $\mathrm{P}_{\mathrm{i}}$ with saturation of $\gamma$-ATP; $M_{0}$, magnetization of $P_{i}$ with saturation at a downfield frequency, equidistant from $\mathrm{P}_{\mathrm{i}} ; T_{1}^{\prime}$, apparent longitudinal relaxation time of $\mathrm{P}_{\mathrm{i}}$ with saturation of $\gamma$-ATP; $T_{1}$, intrinsic longitudinal relaxation time of $\mathrm{P}_{\mathrm{i}} ; k_{\mathrm{Pi} \rightarrow \mathrm{ATP}}, \mathrm{P}_{\mathrm{i}} \rightarrow \mathrm{ATP}$ exchange rate constant; $V_{\mathrm{ATP}}$, resting ATP synthesis flux.

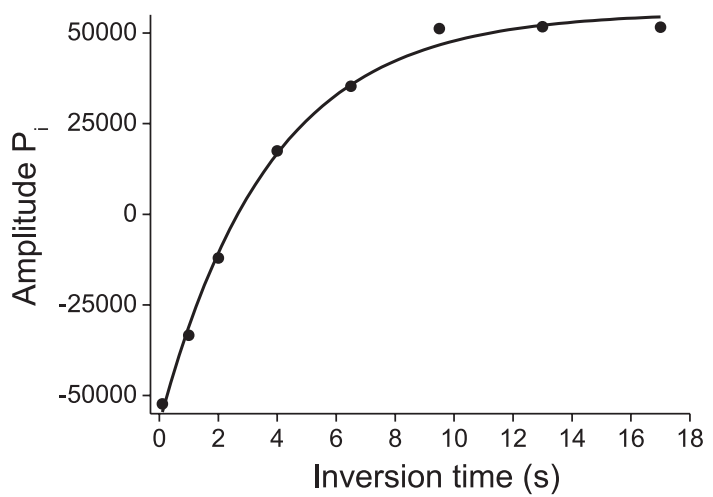

Fig. 2. $\mathrm{P}_{\mathrm{i}}$ amplitudes obtained from an inversion recovery experiment with inversion times of $0.01,1,2,4,6.5,9.5,13$, and $17 \mathrm{~s}$ and with saturation of the $\gamma$-ATP peak. A mono-exponential three-paramenter function (dark line) was fit to the actual data (filled circles) to determine the apparent longitudal relaxation time $\left(T_{1}^{\prime}\right)$, which was $3.75 \mathrm{~s}$ for this example.

mitochondrial dysfunction to establish the most appropriate method for assessment of in vivo skeletal muscle mitochondrial function. Two weeks of treatment with the complex I inhibitor DPI induced mitochondrial dysfunction, as evidenced by a $20 \%$ lower oxygen consumption rate in isolated mitochondria from DPI-treated rats oxidizing pyruvate plus malate. This was paralleled by a $46 \%$ decrease in in vivo oxidative capacity, determined from postexercise $\mathrm{PCr}$ recovery. Interestingly, no significant difference in resting ST-based ATP synthesis flux was observed between DPI-treated rats and controls.

DPI is a nonspecific irreversible inhibitor of flavoenzymes, which causes covalent phenylation of either the flavin or the adjacent amino acid and heme groups of the proteins due to reduction of DPI to its diphenyleneiodonyl radical form during electron transport through the flavin moieties of the enzymes (35). The effects of DPI on mitochondrial function have been studied extensively in vitro $(14,20,44)$. The acute inhibitory effect of DPI in submitochondrial particles and isolated mitochondria prepared from different rat tissues is primarily related to irreversible inhibition of the respiratory chain complex I, which contains flavin adenine dinucleotide as the enzyme cofactor $(14,44)$. It has been shown that DPI also decreases succinate state 3 oxidation in isolated rat skeletal muscle
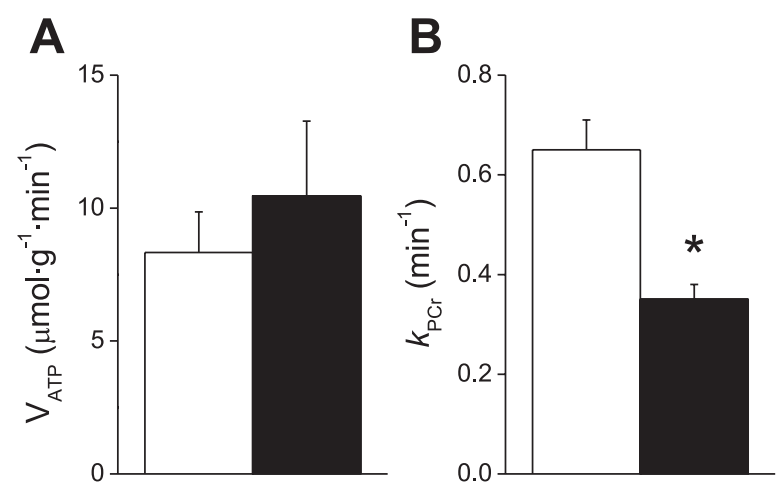

Fig. 3. A: resting ATP synthesis flux ( $V_{\mathrm{ATP}}$; data are from $n=7$ control and $n=8$ DPI-treated animals) measured by ${ }^{31} \mathrm{P}$ saturation transfer magnetic resonance spectroscopy (MRS); $B$ : $\mathrm{PCr}$ recovery rate constant $\left(k_{\mathrm{PCr}} ; n=8\right.$ for both groups) measured with dynamic ${ }^{31} \mathrm{P}$ MRS after muscle stimulation. Open bars, control animals; filled bars, DPI-treated rats. ${ }^{*} P<0.05$ compared with controls. 


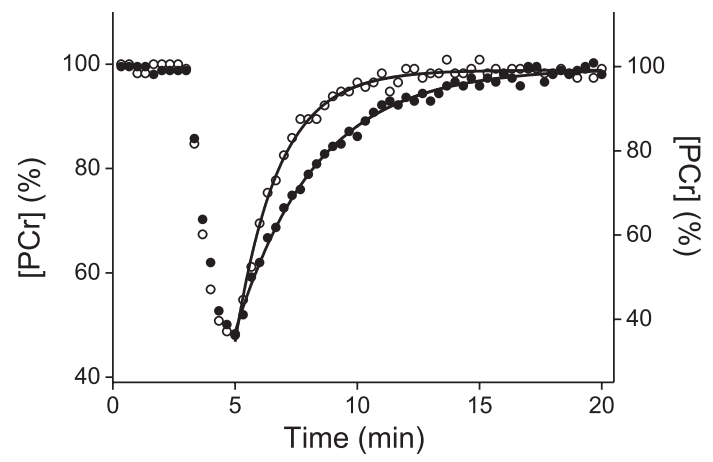

Fig. 4. Representative examples of relative $\mathrm{PCr}$ concentrations during rest, muscle stimulation, and recovery (time resolution $=20 \mathrm{~s}$ ) for a control animal (open symbols) and a DPI-treated rat (filled symbols). PCr concentrations are expressed as a percentage of the resting PCr concentration (left $y$-axis, control rat; right $y$-axis, DPI-treated rat). Monoexponential functions (dark lines) were fit to the recovery data, and the $\mathrm{PCr}$ recovery rate constants were 0.61 and 0.31 $\mathrm{min}^{-1}$ for the control and DPI-treated animal, respectively.

mitochondria, suggesting additional inhibition of respiratory chain complex II (15). However, the observation that this inhibition is dependent on the chloride concentration in the assay medium indicates a different potency or mechanism of action of DPI on complex II (19), which may be related to the fact that complex I and II contain a different flavin cofactor (i.e., complex II contains flavin mononucleotide). Furthermore, it has been shown that the transport of respiratory substrates into the mitochondrial matrix in isolated rat liver mitochondria is not affected by DPI $(13,20)$.

One may expect that the irreversible modifications of the respiratory chain complexes I and II observed in vitro also occur in vivo in animals chronically treated with DPI. Indeed, it has been shown that state 3 oxygen consumption, driven by oxidation of various NADH-delivering substrates, was significantly decreased in mitochondria isolated from gastrocnemius and soleus muscles of rats after 14 days of daily DPI treatment compared with healthy controls (9). This effect could be fully explained by specific inhibition of complex I activity. In agreement, we found that DPI treatment of similar duration as in Ref. 9 results in a significant and comparable decrease in pyruvate plus malate-driven oxygen consumption in state 3 in mitochondria isolated from TA muscle. In addition, we observed a small (12\%) but significant decrease in the succinatedriven oxygen consumption in state 3 . The available published data on the effects of in vivo DPI treatment on succinate-driven state 3 oxygen consumption in isolated skeletal muscle mitochondria are scarce and contradictory. Cooper et al. (9) found no significant impairment of succinate-driven state 3 oxygen consumption in isolated skeletal muscle mitochondria, whereas Hayes et al. (15) reported an $80 \%$ decrease in state 3 succinate oxidation in skeletal muscle mitochondria isolated from DPItreated animals compared with controls. The different results are likely due to differences in the concentration of chloride in the assay medium, which affects the potency of DPI to inhibit succinate-driven state 3 oxygen consumption (see above) (19). Because of the low intracellular chloride concentration, the most important mode of action of DPI in vivo is probably inhibition of complex I.

In the present study, mtDNA copy number in TA muscle was similar for DPI-treated and control rats, indicating that
DPI treatment did not affect mitochondrial biogenesis. This is in agreement with Cooper et al. (9) who showed similar activities of citrate synthase and other TCA cycle enzymes in the muscle of DPI-treated animals compared with healthy controls. The observation that DPI treatment does not cause compensatory stimulation of mitochondrial biogenesis simplifies the interpretation of the in vivo determined $\mathrm{PCr}$ recovery rate constant $k_{\mathrm{PCr}}$. It implies that the decrease in $k_{\mathrm{PCr}}$ in TA muscle of DPI-treated animals results from impaired intrinsic mitochondrial function rather than decreased mitochondrial number. However, the discrepancy in the magnitude of the effect of DPI observed on the in vivo determined $k_{\mathrm{PCr}}(46 \%$ decrease) and the in vitro mitochondrial function (20\% decrease of state 3 oxygen consumption with pyruvate plus malate and $12 \%$ decrease of state 3 oxygen consumption with succinate plus malate) suggests that other factors than inhibition of the respiratory chain complex I and complex II may additionally affect PCr recovery in vivo. For example, inhibition of the creatine kinase reaction by DPI could slow down the recovery of $\mathrm{PCr}$ in vivo. However, from our ${ }^{31} \mathrm{P}$ ST data no such inhibitory effect was observed for the $\mathrm{PCr} \rightarrow \mathrm{ATP}$ flux (data not shown), which is in agreement with observations in a previous study (15). Alternatively, a lowered muscle tissue perfusion could be responsible for a slower $\mathrm{PCr}$ recovery by reducing the availability of oxygen and substrate. DPI has been shown to inhibit endothelial nitric oxide synthase (eNOS), an enzyme involved in vascular vasodilation (54). Inhibition of eNOS lowers muscle blood flow during recovery from exercise in humans $(8,47)$ and therefore we cannot exclude that a lower muscle perfusion in DPI-treated animals may have affected $k_{\mathrm{PCr}}$.

In contrast to the oxygen consumption in isolated mitochondria and the in vivo PCr recovery, resting ST-based ATP synthesis flux $V_{\text {ATP }}$ was not affected by DPI treatment. Mitochondrial ATP synthesis is a demand-driven process regulated by several error signals. Most investigated is the feedback control loop involving changes in the extramitochondrial concentrations of the ATP hydrolysis products $\operatorname{ADP}(23,25,66)$ and, to a lesser extent, $P_{i}(66)$. To interpret ATP synthesis flux data in terms of mitochondrial function, it is essential to take the error signals; i.e., concentrations of ADP and $\mathrm{P}_{\mathrm{i}}$, into account (26). A lower ATP synthesis flux in combination with low error signals simply represents a lower ATP demand. On the other hand, a lower ATP synthesis flux in combination with normal or high error signals would indeed imply mitochondrial dysfunction or a decrease in the density of mitochondria. In our study, DPI-treated rats had both normal resting ATP synthesis flux and a normal resting $P_{i}$ concentration, whereas the ADP concentration was slightly, but not significantly, elevated with respect to controls. These results imply that the resting ATP demand was not affected by treatment with DPI. The slightly increased ADP level in DPI-treated rats suggests that a higher error signal was needed to maintain a normal ATP synthesis flux. Alternatively, another, yet unidentified, error signal might have been increased in DPI-treated rats to match the normal ATP demand.

Another factor that complicates the interpretation of ${ }^{31} \mathrm{P}$ MRS ST data is that the $V_{\text {ATP }}$ obtained from ${ }^{31} \mathrm{P}$ MRS ST measurements is composed of both mitochondrial $\mathrm{F}_{1} \mathrm{~F}_{0}$-ATP synthase flux and flux through other $\mathrm{P}_{\mathrm{i}} \rightarrow$ ATP pathways, in particular the reactions catalyzed by the glycolytic enzymes glyceraldehyde-3-phosphate dehydrogenase (GAPDH) and 
phosphoglycerate kinase (PGK). Although the net glycolytic contribution to the production of ATP (via GAPDH and PGK) versus that of oxidative phosphorylation is small (22), these enzymes catalyze a coupled near-equilibrium reaction, and consequently, exchange between $\mathrm{P}_{\mathrm{i}}$ and ATP may greatly exceed the net glycolytic flux (4). Experimental proof for glycolytic exchange between $\mathrm{P}_{\mathrm{i}}$ and ATP came from ${ }^{31} \mathrm{P}$ MRS ST experiments in yeast. $\mathrm{P}_{\mathrm{i}} \rightarrow$ ATP exchange was inhibited in yeast by iodoacetate, an irreversible inhibitor of GAPDH (6), whereas in anaerobic yeast cells overexpressing PGK, $\mathrm{P}_{\mathrm{i}} \rightarrow$ ATP exchange was increased (2). ${ }^{31} \mathrm{P}$ MRS ST experiments performed on perfused rat hearts showed that the glycolytic exchange reaction contributes significantly to the measured $V_{\text {ATP }}$ and that only when glycolytic activity was inhibited, the measured $V_{\text {ATP }}$ displayed a linear dependence on oxygen consumption and thus represents mitochondrial $\mathrm{F}_{1} \mathrm{~F}_{0^{-}}$ ATP synthase flux (27). For rat skeletal muscle, values for resting ATP turnover from ${ }^{31} \mathrm{P}$ MRS ST experiments are about five times higher compared with figures derived from oxygen consumption rates, whereas in human muscle the difference is even larger (reviewed in Ref. 26). This indicates that the contribution of glycolytic exchange flux to the measured $V_{\text {ATP }}$ from ${ }^{31} \mathrm{P}$ MRS ST experiments in resting skeletal muscle can be as much as $80 \%$. Up to this point, it has been assumed that the mitochondrial $\mathrm{F}_{1} \mathrm{~F}_{0}$-ATP synthase flux, which constitutes only a small part of the total $V_{\text {ATP }}$ measured, is unidirectional. However, it has been shown that at low rates of respiration (e.g., resting muscle) the $\mathrm{F}_{1} \mathrm{~F}_{0}$-ATP synthase reaction is near to equilibrium and that mitochondrial exchange between $P_{i}$ and ATP can make a significant contribution to the measured $V_{\text {ATP }}$ (50). Taken together, if there would have been an effect of DPI on the rate of net resting mitochondrial ATP production, this effect might not be measurable due to the large contribution of glycolytic exchange flux and possibly also a significant contribution of mitochondrial exchange flux to the total measured $V_{\text {ATP. }}$ To create better conditions for detecting a defect in skeletal muscle mitochondrial oxidative phosphorylation, ${ }^{31} \mathrm{P}$ MRS ST experiments would need to be performed during steady-state muscle contraction, when the $\mathrm{F}_{1} \mathrm{~F}_{0}$-ATP synthase reaction is largely unidirectional and the flux through the $\mathrm{F}_{1} \mathrm{~F}_{0}$-ATP synthase is much larger than the glycolytic exchange flux (3). However, it is very challenging to maintain steady-state muscle contractions during the lengthy ${ }^{31} \mathrm{P}$ MRS ST experiments, and this might in particular be a problem in patient groups. Moreover, in such an experiment it is crucial to achieve similar relative workloads in different subjects or animals.

Most ${ }^{31} \mathrm{P}$ MRS ST studies investigating the role of skeletal muscle mitochondrial function in the development of IR and T2D lack a proper discussion about the error signals; i.e., the concentrations of $\mathrm{P}_{\mathrm{i}}$ and ADP. The lower $V_{\mathrm{ATP}}$ in IR subjects and animal models and patients with T2D $(28,38-40,56,67)$ might be explained by a lower $\mathrm{P}_{\mathrm{i}}$ concentration (39), caused by reduced sarcolemmal $P_{i}$ uptake in insulin-resistant muscle (41), rather than a decrease in the $\mathrm{P}_{\mathrm{i}} \rightarrow$ ATP exchange rate constant $k_{\mathrm{Pi} \rightarrow \mathrm{ATP}}$. Furthermore, it has been shown that hyperinsulinemia decreases the intracellular $\mathrm{pH}$ (59), resulting in a lower ADP concentration and therefore a lower error signal for oxidative ATP synthesis. In addition, all ${ }^{31} \mathrm{P}$ MRS ST studies investigating the role of skeletal muscle mitochondrial function in the development of IR and T2D were performed in resting skeletal muscle $(28,38-40,56,61,67)$. As was explained in the previous paragraph, in resting skeletal muscle the contribution of $\mathrm{F}_{1} \mathrm{~F}_{0}$ - $\mathrm{ATP}$ synthesis flux to the total measured $V_{\mathrm{ATP}}$ will be relatively low, which further complicates the interpretation of these measurements. In a recent study, measurements of both $\mathrm{PCr}$ recovery and resting ATP synthesis flux were performed in T2D patients and healthy controls (61). The half-times of $\mathrm{PCr}$ recovery were not different between groups and also resting ATP synthesis flux was not impaired in the patients with T2D compared with controls, whereas concentrations of $\mathrm{P}_{\mathrm{i}}$ and ADP were similar for both groups. In addition, half-times of PCr recovery were not significantly correlated with resting ATP synthesis fluxes, which is in agreement with the results of the present study. It should be noted that the animal model that we used in this study is a model of mitochondrial dysfunction but that it does not represent a model for IR of T2D. On the contrary, it has been shown that DPI can induce hypoglycemia $(19,20)$.

In conclusion, the rate constant of $\mathrm{PCr}$ recovery measured with dynamic ${ }^{31} \mathrm{P}$ MRS after exercise provides a more sensitive measure of skeletal muscle mitochondrial function than the ATP synthesis flux determined with ${ }^{31} \mathrm{P}$ ST in the resting state. The ATP synthesis flux itself represents the ATP demand of the muscle, and to interpret the data in terms of mitochondrial function it is necessary to take the errors signals; i.e., the concentrations of ADP and $\mathrm{P}_{\mathrm{i}}$, into account. Moreover, the $V_{\text {ATP }}$ obtained from a ${ }^{31} \mathrm{P}$ ST experiment in the resting state is dominated by glycolytic exchange flux. To detect a defect in mitochondrial oxidative phosphorylation the latter experiment would need to be done in exercising muscle.

\section{ACKNOWLEDGMENTS}

The authors thank Joep van Lier for support in fitting the ${ }^{31} \mathrm{P}$ MR spectra and Dr. Jeroen Jeneson for stimulating discussions.

\section{GRANTS}

The work of J.Ciapaite is financed by the Netherlands Consortium for Systems Biology (NCSB), which is part of the Netherlands Genomics Initiative/Netherlands Organisation for Scientific Research. J. J. Prompers is supported by a VIDI grant from the Netherlands Organisation for Scientific Research (VIDI Grant Number 700.58.421).

\section{DISCLOSURES}

No conflicts of interest, financial or otherwise, are declared by the author(s).

\section{REFERENCES}

1. Brehm A, Krssak M, Schmid AI, Nowotny P, Waldhausl W, Roden M. Increased lipid availability impairs insulin-stimulated ATP synthesis in human skeletal muscle. Diabetes 55: 136-140, 2006.

2. Brindle KM. 31P NMR magnetization-transfer measurements of flux between inorganic phosphate and adenosine $5^{\prime}$-triphosphate in yeast cells genetically modified to overproduce phosphoglycerate kinase. Biochemistry 27: 6187-6196, 1988.

3. Brindle KM, Blackledge MJ, Challiss RA, Radda GK. 31P NMR magnetization-transfer measurements of ATP turnover during steady-state isometric muscle contraction in the rat hind limb in vivo. Biochemistry 28: 4887-4893, 1989.

4. Brindle KM, Radda GK. 31P-NMR saturation transfer measurements of exchange between Pi and ATP in the reactions catalysed by glyceraldehyde-3-phosphate dehydrogenase and phosphoglycerate kinase in vitro. Biochim Biophys Acta 928: 45-55, 1987.

5. Brown TR, Ugurbil K, Shulman RG. 31P nuclear magnetic resonance measurements of ATPase kinetics in aerobic Escherichia coli cells. Proc Natl Acad Sci USA 74: 5551-5553, 1977. 
6. Campbell-Burk SL, Jones KA, Shulman RG. 31P NMR saturationtransfer measurements in Saccharomyces cerevisiae: characterization of phosphate exchange reactions by iodoacetate and antimycin A inhibition. Biochemistry 26: 7483-7492, 1987.

7. Ciapaite J, Bakker SJ, Van Eikenhorst G, Wagner MJ, Teerlink T, Schalkwijk CG, Fodor M, Ouwens DM, Diamant M, Heine RJ, Westerhoff HV, Krab K. Functioning of oxidative phosphorylation in liver mitochondria of high-fat diet fed rats. Biochim Biophys Acta 1772: 307-316, 2007.

8. Clifford PS, Hellsten Y. Vasodilatory mechanisms in contracting skeletal muscle. J Appl Physiol 97: 393-403, 2004.

9. Cooper J, Petty R, Hayes D, Morgan-Hughes J, Clark J. Chronic administration of the oral hypoglycaemic agent diphenyleneiodonium to rats. An animal model of impaired oxidative phosphorylation (mitochondrial myopathy). Biochem Pharmacol 37: 687-694, 1988.

10. Cooper JM, Petty RK, Hayes DJ, Challiss RA, Brosnan MJ, Shoubridge EA, Radda GK, Morgan-Hughes JA, Clark JB. An animal model of mitochondrial myopathy: a biochemical and physiological in vestigation of rats treated in vivo with the NADH-CoQ reductase inhibitor, diphenyleneiodonium. J Neurol Sci 83: 335-347, 1988.

11. De Feyter HM, Lenaers E, Houten SM, Schrauwen P, Hesselink MK, Wanders RJ, Nicolay K, Prompers JJ. Increased intramyocellular lipid content but normal skeletal muscle mitochondrial oxidative capacity throughout the pathogenesis of type 2 diabetes. FASEB J 22: 3947-3955, 2008.

12. De Feyter HM, van den Broek NM, Praet SF, Nicolay K, van Loon LJ, Prompers JJ. Early or advanced stage type 2 diabetes is not accompanied by in vivo skeletal muscle mitochondrial dysfunction. Eur $J$ Endocrinol 158: 643-653, 2008.

13. Gatley SJ, Sherratt HS. The effects of diphenyleneiodonium and of 2,4-dichlorodiphenyleneiodonium on mitochondrial reactions. Mechanism of the inhibition of oxygen uptake as a consequence of the catalysis of the chloride/hydroxyl-ion exchange. Biochem J 158: 317-326, 1976.

14. Gatley SJ, Sherratt SA. The effects of diphenyleneiodonium on mitochondrial reactions. Relation of binding of diphenylene [ $\left.{ }^{125} \mathrm{I}\right]$ iodonium to mitochondria to the extent of inhibition of oxygen uptake. Biochem $J 158$ 307-315, 1976.

15. Hayes DJ, Byrne E, Shoubridge EA, Morgan-Hughes JA, Clark JB. Experimentally induced defects of mitochondrial metabolism in rat skeletal muscle. Biological effects of the NADH: coenzyme Q reductase inhibitor diphenyleneiodonium. Biochem J 229: 109-117, 1985.

16. He J, Watkins S, Kelley DE. Skeletal muscle lipid content and oxidative enzyme activity in relation to muscle fiber type in type 2 diabetes and obesity. Diabetes 50: 817-823, 2001.

17. Heilbronn LK, Gan SK, Turner N, Campbell LV, Chisholm DJ. Markers of mitochondrial biogenesis and metabolism are lower in overweight and obese insulin-resistant subjects. J Clin Endocrinol Metab 92: 1467-1473, 2007.

18. Hojlund K, Wrzesinski K, Larsen PM, Fey SJ, Roepstorff P, Handberg A, Dela F, Vinten J, McCormack JG, Reynet C, Beck-Nielsen $\mathbf{H}$. Proteome analysis reveals phosphorylation of ATP synthase beta-subunit in human skeletal muscle and proteins with potential roles in type 2 diabetes. J Biol Chem 278: 10436-10442, 2003.

19. Holland PC, Clark MG, Bloxham DP, Lardy HA. Mechanism of action of the hypoglycemic agent diphenyleneiodonium. J Biol Chem 248: 6050-6056, 1973.

20. Holland PC, Sherratt HS. Biochemical effects of the hypoglycaemic compound diphenyleneiodonnium. Catalysis of anion-hydroxyl ion exchange across the inner membrane of rat liver mitochondria and effects on oxygen uptake. Biochem J 129: 39-54, 1972.

21. Holloszy JO. Skeletal muscle "mitochondrial deficiency" does not mediate insulin resistance. Am J Clin Nutr 89: 463S-466S, 2009.

22. Hood DA, Gorski J, Terjung RL. Oxygen cost of twitch and tetanic isometric contractions of rat skeletal muscle. Am J Physiol Endocrinol Metab 250: E449-E456, 1986.

23. Jeneson JA, Schmitz JP, van den Broek NM, van Riel NA, Hilbers PA, Nicolay K, Prompers JJ. Magnitude and control of mitochondrial sensitivity to ADP. Am J Physiol Endocrinol Metab 297: E774-E784, 2009.

24. Kelley DE, He J, Menshikova EV, Ritov VB. Dysfunction of mitochondria in human skeletal muscle in type 2 diabetes. Diabetes 51: 2944-2950, 2002.

25. Kemp GJ. Interactions of mitochondrial ATP synthesis and the creatine kinase equilibrium in skeletal muscle. J Theor Biol 170: 239-246, 1994.
26. Kemp GJ. The interpretation of abnormal 31P magnetic resonance saturation transfer measurements of $\mathrm{Pi} / \mathrm{ATP}$ exchange in insulin-resistant skeletal muscle. Am J Physiol Endocrinol Metab 294: E640-E642, 2008.

27. Kingsley-Hickman PB, Sako EY, Mohanakrishnan P, Robitaille PM, From AH, Foker JE, Ugurbil K. 31P NMR studies of ATP synthesis and hydrolysis kinetics in the intact myocardium. Biochemistry 26: 7501$7510,1987$.

28. Laurent D, Yerby B, Deacon R, Gao J. Diet-induced modulation of mitochondrial activity in rat muscle. Am J Physiol Endocrinol Metab 293: E1169-E1177, 2007.

29. Lawson JW, Veech RL. Effects of $\mathrm{pH}$ and free $\mathrm{Mg} 2+$ on the Keq of the creatine kinase reaction and other phosphate hydrolyses and phosphate transfer reactions. J Biol Chem 254: 6528-6537, 1979.

30. Majander A, Finel M, Wikstrom M. Diphenyleneiodonium inhibits reduction of iron-sulfur clusters in the mitochondrial NADH-ubiquinone oxidoreductase (Complex I). J Biol Chem 269: 21037-21042, 1994.

31. Mogensen M, Sahlin K, Fernstrom M, Glintborg D, Vind BF, BeckNielsen H, Hojlund K. Mitochondrial respiration is decreased in skeletal muscle of patients with type 2 diabetes. Diabetes 56: 1592-1599, 2007.

32. Mootha VK, Lindgren CM, Eriksson KF, Subramanian A, Sihag S, Lehar J, Puigserver P, Carlsson E, Ridderstrale M, Laurila E, Houstis N, Daly MJ, Patterson N, Mesirov JP, Golub TR, Tamayo P, Spiegelman B, Lander ES, Hirschhorn JN, Altshuler D, Groop LC. PGC-1alpha-responsive genes involved in oxidative phosphorylation are coordinately downregulated in human diabetes. Nat Genet 34: 267-273, 2003.

33. Morino K, Petersen KF, Dufour S, Befroy D, Frattini J, Shatzkes N, Neschen S, White MF, Bilz S, Sono S, Pypaert M, Shulman GI. Reduced mitochondrial density and increased IRS-1 serine phosphorylation in muscle of insulin-resistant offspring of type 2 diabetic parents. $J$ Clin Invest 115: 3587-3593, 2005.

34. Morino K, Petersen KF, Shulman GI. Molecular mechanisms of insulin resistance in humans and their potential links with mitochondrial dysfunction. Diabetes 55, Suppl 2: S9-S15, 2006

35. O'Donnell VB, Smith GC, Jones OT. Involvement of phenyl radicals in iodonium inhibition of flavoenzymes. Mol Pharmacol 46: 778-785, 1994.

36. Palladino GW, Wood JJ, Proctor HJ. Modified freeze clamp technique for tissue assay. J Surg Res 28: 188-190, 1980.

37. Patti ME, Butte AJ, Crunkhorn S, Cusi K, Berria R, Kashyap S, Miyazaki Y, Kohane I, Costello M, Saccone R, Landaker EJ, Goldfine AB, Mun E, DeFronzo R, Finlayson J, Kahn CR, Mandarino LJ. Coordinated reduction of genes of oxidative metabolism in humans with insulin resistance and diabetes: potential role of PGC1 and NRF1. Proc Natl Acad Sci USA 100: 8466-8471, 2003.

38. Petersen KF, Befroy D, Dufour S, Dziura J, Ariyan C, Rothman DL, DiPietro L, Cline GW, Shulman GI. Mitochondrial dysfunction in the elderly: possible role in insulin resistance. Science 300: 1140-1142, 2003.

39. Petersen KF, Dufour S, Befroy D, Garcia R, Shulman GI. Impaired mitochondrial activity in the insulin-resistant offspring of patients with type 2 diabetes. $N$ Engl J Med 350: 664-671, 2004.

40. Petersen KF, Dufour S, Shulman GI. Decreased insulin-stimulated ATP synthesis and phosphate transport in muscle of insulin-resistant offspring of type 2 diabetic parents. PLoS Med 2: e233, 2005.

41. Polgreen KE, Kemp GJ, Leighton B, Radda GK. Modulation of Pi transport in skeletal muscle by insulin and IGF-1. Biochim Biophys Acta 1223: 279-284, 1994.

42. Quistorff B, Johansen L, Sahlin K. Absence of phosphocreatine resynthesis in human calf muscle during ischaemic recovery. Biochem J 291: 681-686, 1993.

43. Rabol R, Boushel R, Dela F. Mitochondrial oxidative function and type 2 diabetes. Appl Physiol Nutr Metab 31: 675-683, 2006.

44. Ragan CI, Bloxham DP. Specific labelling of a constituent polypeptide of bovine heart mitochondrial reduced nicotinamide-adenine dinucleotideubiquinone reductase by the inhibitor diphenyleneiodonium. Biochem $J$ 163: 605-615, 1977

45. Ritov VB, Menshikova EV, He J, Ferrell RE, Goodpaster BH, Kelley DE. Deficiency of subsarcolemmal mitochondria in obesity and type 2 diabetes. Diabetes 54: 8-14, 2005.

46. Sahlin K. Intracellular $\mathrm{pH}$ and energy metabolism in skeletal muscle of man. With special reference to exercise. Acta Physiol Scand Suppl 455: 1-56, 1978.

47. Saltin B, Radegran G, Koskolou MD, Roach RC. Skeletal muscle blood flow in humans and its regulation during exercise. Acta Physiol Scand 162: 421-436, 1998. 
48. Schrauwen-Hinderling VB, Kooi ME, Hesselink MK, Jeneson JA, Backes WH, van Echteld CJ, van Engelshoven JM, Mensink M, Schrauwen P. Impaired in vivo mitochondrial function but similar intramyocellular lipid content in patients with type 2 diabetes mellitus and BMI-matched control subjects. Diabetologia 50: 113-120, 2007.

49. Schrauwen-Hinderling VB, Roden M, Kooi ME, Hesselink MK, Schrauwen P. Muscular mitochondrial dysfunction and type 2 diabetes mellitus. Curr Opin Clin Nutr Metab Care 10: 698-703, 2007.

50. Sheldon JG, Williams SP, Fulton AM, Brindle KM. 31P NMR magnetization transfer study of the control of ATP turnover in Saccharomyces cerevisiae. Proc Natl Acad Sci USA 93: 6399-6404, 1996.

51. Short KR, Nair KS, Stump CS. Impaired mitochondrial activity and insulin-resistant offspring of patients with type 2 diabetes. $N$ Engl J Med 350: 2419-2421; author reply 2419-2421, 2004.

52. Simoneau JA, Kelley DE. Altered glycolytic and oxidative capacities of skeletal muscle contribute to insulin resistance in NIDDM. J Appl Physiol 83: $166-171,1997$.

53. Sreekumar R, Nair KS. Skeletal muscle mitochondrial dysfunction \& diabetes. Indian J Med Res 125: 399-410, 2007.

54. Stuehr DJ, Fasehun OA, Kwon NS, Gross SS, Gonzalez JA, Levi R, Nathan CF. Inhibition of macrophage and endothelial cell nitric oxide synthase by diphenyleneiodonium and its analogs. FASEB J 5: 98-103, 1991.

55. Szendroedi J, Roden M. Mitochondrial fitness and insulin sensitivity in humans. Diabetologia 51: 2155-2167, 2008.

56. Szendroedi J, Schmid AI, Chmelik M, Toth C, Brehm A, Krssak M, Nowotny P, Wolzt M, Waldhausl W, Roden M. Muscle mitochondrial ATP synthesis and glucose transport/phosphorylation in type 2 diabetes. PLoS Med 4: e154, 2007.

57. Szuhai K, Ouweland J, Dirks R, Lemaitre M, Truffert J, Janssen G, Tanke H, Holme E, Maassen J, Raap A. Simultaneous A8344G heteroplasmy and mitochondrial DNA copy number quantification in myoclonus epilepsy and ragged-red fibers (MERRF) syndrome by a multiplex molecular beacon based real-time fluorescence PCR. Nucleic Acids Res 29: E13, 2001.

58. Taylor DJ, Bore PJ, Styles P, Gadian DG, Radda GK. Bioenergetics of intact human muscle. A 31P nuclear magnetic resonance study. Mol Biol Med 1: 77-94, 1983.
59. Taylor DJ, Coppack SW, Cadoux-Hudson TA, Kemp GJ, Radda GK, Frayn KN, Ng LL. Effect of insulin on intracellular $\mathrm{pH}$ and phosphate metabolism in human skeletal muscle in vivo. Clin Sci (Lond) 81: 123-128, 1991.

60. Trautschold I, Lamprecht W, Schweitzer G. Nucleotides, Coenzymes and related compounds. In: Methods of Enzymatic Analysis, edited by Bergmeyer H, Wiley-VCH, 1985.

61. Trenell MI, Hollingsworth KG, Lim EL, Taylor R. Increased daily walking improves lipid oxidation without changes in mitochondrial function in Type 2 diabetes. Diabetes Care 31: 1644-1649, 2008.

62. van den Broek NM, Ciapaite J, De Feyter HM, Houten SM, Wanders RJ, Jeneson JA, Nicolay K, Prompers JJ. Increased mitochondrial content rescues in vivo muscle oxidative capacity in long-term high-fatdiet-fed rats. FASEB J 24: 1354-1364, 2010.

63. van den Broek NM, De Feyter HM, de Graaf L, Nicolay K, Prompers JJ. Intersubject differences in the effect of acidosis on phosphocreatine recovery kinetics in muscle after exercise are due to differences in proton efflux rates. Am J Physiol Cell Physiol 293: C228-C237, 2007.

64. Vicini P, Kushmerick MJ. Cellular energetics analysis by a mathematical model of energy balance: estimation of parameters in human skeletal muscle. Am J Physiol Cell Physiol 279: C213-C224, 2000.

65. Wagenmakers AJ. Insulin resistance in the offspring of parents with type 2 diabetes. PLoS Med 2: e289, 2005.

66. Wu F, Jeneson JA, Beard DA. Oxidative ATP synthesis in skeletal muscle is controlled by substrate feedback. Am J Physiol Cell Physiol 292: C115-C124, 2007.

67. Yerby B, Deacon R, Beaulieu V, Liang J, Gao J, Laurent D. Insulinstimulated mitochondrial adenosine triphosphate synthesis is blunted in skeletal muscles of high-fat-fed rats. Metabolism 57: 1584-1590, 2008.

68. Yu C, Chen Y, Cline GW, Zhang D, Zong H, Wang Y, Bergeron R, Kim JK, Cushman SW, Cooney GJ, Atcheson B, White MF, Kraegen EW, Shulman GI. Mechanism by which fatty acids inhibit insulin activation of insulin receptor substrate-1 (IRS-1)-associated phosphatidylinositol 3-kinase activity in muscle. J Biol Chem 277: 50230-50236, 2002 . 